\title{
Dificuldade de aprendizagem na perspectiva das inteligências múltiplas: um estudo com um grupo de crianças brasileiras
}

\author{
Vera Lúcia Teixeira da Silva \\ Rede Pública do Estado de São Paulo, Brasil \\ Vilma Leni Nista-Piccolo \\ Universidade São Judas Tadeu, Brasil
}

\begin{abstract}
Resumo
O texto apresenta um estudo realizado com treze crianças brasileiras, matriculadas na quarta série do ensino fundamental da rede pública do Estado de São Paulo, diagnosticadas como possuidoras de Dificuldade de Aprendizagem. O objetivo foi investigar a possibilidade de ampliar a aquisição, manifestação e expressão do conhecimento, por parte dessas crianças. Partindo-se da análise bibliográfica sobre Aprendizagem, Dificuldade de Aprendizagem e Inteligências Múltiplas, realizaram-se Intervenções Pedagógicas, visando estimular a pluralidade intelectual desses estudantes. Como método de análise optou-se pelo Paradigma Indiciário sugerido por Ginzburg (1989). Os dados levantados em entrevistas e observações durante a realização das Intervenções Pedagógicas apontaram sinais que podem ter favorecido a Dificuldade de Aprendizagem no contexto escolar. Após o período das Intervenções Pedagógicas, percebeu-se que a motivação, a disciplina, a interação, a auto-estima e a expressividade melhoraram consideravelmente. Além disso, os dados apontaram indícios que favorecem a aprendizagem, construídos no percurso da realização das Intervenções Pedagógicas.
\end{abstract}

Palavras-chave

Aprendizagem; Dificuldade de aprendizagem; Inteligências múltiplas

\section{Introdução}

Nos últimos anos, apesar de algumas medidas governamentais, amparadas por muitos estudos e discussões sobre a educação brasileira, o fracasso escolar ainda se impõe de forma alarmante. 
O sistema escolar com suas várias reformas ampliou o número de vagas, mas não desenvolveu uma ação que tornasse eficiente essa questão e garantisse o cumprimento daquilo que o justifica, ou seja, o acesso ao conhecimento. Atualmente, a tentativa de resolver as dificuldades de aprendizagem apresentadas pelas crianças ainda é pela reprovação de série. Alguns autores como Ciasca (2003) e Neira (2003) apontam que apesar dos valores numéricos relacionados com reprovação e evasão terem diminuído, muitos alunos continuam na mesma situação, ou seja, "sem condições de aprender".

Além disso, estudos revelam que apesar dos múltiplos fatores que interferem nas causas do fracasso escolar, a maior parte das pesquisas sobre crise educacional, insiste nas dificuldades que os estudantes têm em dominar objetivos manifestos pela escola sem, contudo, considerar os meios utilizados pelos professores para alcançarem estes objetivos (Gardner, 1994).

Até mesmo escolas bem conceituadas enfatizam como sinais do conhecimento adquirido, apenas o desempenho expressado no que está dentro da padronização do sistema escolar. Por conseguinte, é comum crianças fracassarem diante das exigências impostas pela escola e serem classificadas como detentoras de Dificuldades de Aprendizagem (DA).

Ao considerar que a aprendizagem sofre a influência de inúmeras variáveis, torna-se ainda mais complexo o campo de investigação sobre as Dificuldades de Aprendizagem. Ao refletir sobre esses temas deve-se considerar o contexto cultural, a diversidade $e$ as peculiaridades apresentadas, que são características inatas do ser humano. Nessa perspectiva, dependendo do contexto, pode ser viável destacar que os estudantes aprendem de modos diferentes, cada um da sua própria maneira.

Nesse sentido, Gardner (1999; 1994; 2000), em sua Teoria das Inteligências Múltiplas, destaca as várias Inteligências das crianças, particularmente daquelas que no contexto escolar podem ser consideradas como incapazes de aprender. Segundo o autor, todos os indivíduos são inteligentes, mas de maneiras diferentes. $E$ as Inteligências são aperfeiçoadas, ou não, dependendo dos estímulos que as crianças recebem, e do ambiente cultural que as cercam. Nessa concepção, a escola deveria oferecer uma formação que possibilitasse o desenvolvimento dos potenciais individuais, permitindo e favorecendo situações de aprendizagem que contemplem a pluralidade de manifestação e expressão do intelecto. 
A partir do levantamento desses dados surgiu o interesse em investigar como se dá a questão da Dificuldade de Aprendizagem em situações de estímulos das Inteligências Múltiplas, gerando o seguinte questionamento: Será que situações que estimulam as Múltiplas Inteligências em crianças diagnosticadas como possuidoras de Dificuldades de Aprendizagem, podem ser uma alternativa facilitadora do acesso ao conhecimento?

Sob o embasamento da Teoria das Inteligências Múltiplas (Gardner, 2000), na qual o autor relata que todos apresentam potenciais, os quais, devidamente reconhecidos e estimulados, contribuem para o desenvolvimento global, é que se buscou conhecer e desenvolver algumas práticas pedagógicas.

A amostra delimitada nesse estudo constituiu-se em um grupo de treze estudantes brasileiros, matriculados na quarta série do ensino fundamental de uma Escola Estadual da rede pública de ensino do Estado de São Paulo, os quais foram declarados pela equipe docente e administrativa da escola, como possuidores de DA.

A finalidade principal desse estudo foi investigar a possibilidade de ampliar a expressão do conhecimento, utilizando as múltiplas manifestações de Inteligências, como rotas de acesso no processo ensino e aprendizagem dessas crianças, que segundo diagnóstico escolar, apresentam DA.

Partindo das análises bibliográficas sobre Aprendizagem, DA e Inteligências Múltiplas foram elaboradas propostas pedagógicas de ensino, por meio de situações problemas, com ênfase no trabalho motor, visando estimular a pluralidade intelectual desses estudantes.

Os tópicos a seguir sintetizam aspectos importantes destacados dos temas referentes à Aprendizagem, Dificuldades de Aprendizagem, Teoria das Inteligências múltiplas, bem como suas implicações na aprendizagem, os quais serviram de embasamento para as Intervenções. Posteriormente, apresenta-se o percurso metodológico dessa investigação e a análise dos dados que foi realizada de acordo com o método sugerido por Ginzburg (1989), denominado de "Paradigma Indiciário".

\section{Aprendizagem}

Apesar da aprendizagem ser uma característica inata do ser humano, os processos pelos quais se adquire o conhecimento ainda se constituem em um desafio para estudiosos e pesquisadores das mais diversas áreas. 
Ao abordar esse tema na área educacional, pode ser necessário considerar os aspectos pedagógicos, políticos, culturais e sociais que os permeiam. Nessa ótica, a aprendizagem passa a ser um fenômeno perspectival, ou seja, é passível de uma abordagem por diversas lentes, pois envolve um estado de peculiaridade do ser humano, de acordo com a cultura, a sociedade e, conseqüentemente, com as situações de aprendizagem vivenciadas por cada indivíduo no decorrer de sua história de vida.

A interação social fornece os meios para o desenvolvimento, pois em todo o percurso de vida o indivíduo é, profundamente, influenciado por significações do mundo social. Apesar da trajetória do seu desenvolvimento, em parte ser definido pelo processo de maturação do organismo individual, é o aprendizado que possibilita 0 despertar dos processos internos desse desenvolvimento (Vygotsky, 1991).

Alguns pesquisadores (Gardner, 2006; Smole, 2006; Vecchi, 2006; Zylberberg, 2007) acrescentam que para uma aprendizagem ser concretizada, ela deve ser significativa para quem aprende o que exige uma avaliação da compreensão desses significados por parte do educador e educando. A partir do entendimento do significado parte-se para a relação da situação de aprendizagem que está sendo apresentada com as experiências anteriores e vivências pessoais dos aprendizes.

Além disso, a aprendizagem passa a ser significativa quando transcende métodos de ensino e exige o envolvimento por meio da interação de todas as variáveis que interferem no processo. Essa interação mútua possibilita aos alunos aprenderem por múltiplos caminhos, permitindo as diversas formas de conceber e expressar seus conhecimentos (Gardner, 1994; 2006; Vecchi, 2006; Zylberberg, 2007).

Nessa interação de variáveis, o processo de aprendizagem pode percorrer um caminho não linear, o qual se desvela por meio de indícios, presentes nas relações cognitivas, afetivas, sociais, estabelecidas na história, na cultura e principalmente pela singularidade do próprio sujeito.

Pode-se considerar também que esse tipo de estruturação cognitiva se dá por intermédio de uma seqüência de eventos, única para cada pessoa. Desta forma, o aprendiz pode ser considerado dentro da sua complexidade, com suas características individuais sendo influenciado pelo meio, estando 
sensível a uma infinidade de manifestações, as quais resultam dessa interação dinâmica.

Nessa perspectiva, a construção do conhecimento no ambiente escolar pode conduzir para ações pedagógicas que valorizem a individualidade e o contexto social, reconhecendo e respondendo às necessidades diversificadas de seus alunos, acomodando os diferentes estilos e ritmos de aprendizagem e assegurando educação de qualidade para todos, sem, contudo, abandonar seus objetivos.

No entanto, no contexto escolar, quando o processo ensino aprendizagem não alcança êxito, embora existam outros fatores, as causas geralmente são buscadas somente no estudante, o qual se torna referência de incapacidade, tornando-se o único responsável pelo seu fracasso.

Essas questões suscitam a seguinte reflexão: Se o aprender constitui uma característica que pertence ao indivíduo desde o seu nascimento, compondo sua peculiaridade, a qual está submersa na interação mútua de inúmeras variáveis, o que pode constituir o não aprender?

\section{Dificuldades de aprendizagem}

Estudos revelam que apesar do tema envolver muitas discussões, nas mais diversas áreas, um consenso que parece existir entre os autores é o de que a Dificuldade de Aprendizagem (DA) pode gerar ou mesmo agravar problemas relacionados à adaptação social, convivência e auto-estima do estudante.

Ao realizar um estudo, Osti (2004) observa que $90 \%$ dos professores definem as DA como sendo uma lentidão ou incapacidade do aluno para assimilar informações, sendo revelada quando o aluno não atinge o mínimo esperado. Apenas $10 \%$ dos professores envolvidos na pesquisa apontam DA como sendo a soma de fatores de ordem social, cultural, psicológica e neurológica. Esses resultados revelam que a percepção do professor em relação a DA está diretamente ligada ao aluno, sendo considerada uma característica intrínseca, ou seja, é o seu rendimento, o seu desempenho que irão determinar suas habilidades de aprender.

Nesta ótica, as práticas pedagógicas e a articulação de inúmeras variáveis que interferem no processo de aprender não são consideradas, o 
aluno passa a ser diagnosticado como "capacitado ou incapacitado para aprendizagem" a partir da assimilação de informações.

Ao abordarem o tema, alguns autores como Gardner, Konhaber e Wake (1998); Armstrong (2001); Feldman (2001); Neira (2003); Weisz e Sanchez (2003); Wadsworth (2003) e Zylberberg (2007) esclarecem que as crianças que possuem potenciais que se expressam em dimensões físicas e artísticas, como as artes plásticas, a música, os movimentos corporais, freqüentemente, são as que enfrentam maiores dificuldades no sistema escolar, pois apresentam incompatibilidade com os valores expressos pela escola, nos quais os professores, na maioria das vezes, validam apenas conhecimentos em algumas áreas, sem considerar as diferenças individuais.

Wadsworth (2003) relata que todos os indivíduos apresentam DA. Por muitas razões as facilidades e dificuldades do aprendizado estão relacionadas com o fato de algumas pessoas serem extremamente talentosas em determinadas áreas, como também fracos em outras. $O$ autor esclarece que se o critério para excelência de uma pessoa fosse a capacidade musical, e não o conjunto de notas escolares, certamente outro grupo de alunos seriam rotulados como incapazes para aprender.

O sistema educacional responsabiliza o indivíduo que não aprende como único responsável pela sua incapacidade. Essas ações desvinculam completamente a aprendizagem como possibilidade de desenvolvimento cognitivo do aluno. Sendo que o interesse do sistema consiste nos percentuais de reprovação ou aprovação, por conseguinte, as ações pedagógicas escolares estão inseridas numa pedagogia de exame que sobrepuja todo o processo ensino aprendizagem (Machado, 1997; Patto, 1988; Gardner, 1998; Luckesi, 1999).

Embora os professores defendam teoricamente a inclusão dos alunos com dificuldades em relação à aprendizagem, na prática ainda preconizam que as crianças devem se submeter ao ensino homogêneo, com habilidades e competências comparáveis, aprendendo em um contexto em que o professor sempre ensina de uma mesma maneira traduzindo na formalidade dos conteúdos (Macedo, 2005; Smole, 2006).

Dessa forma, as crianças são excluídas, silenciosamente, do sistema escolar e da sociedade. Os estudantes permanecem no sistema escolar, 
porém não desfrutam de uma pedagogia apropriada que contemple suas reais necessidades educacionais (Neira, 2003; Amaro, 2006).

Corroborando Fernández (1991) declara que não se pode entender o processo somente a partir do aprendiz, tornando-se necessário recorrer ao professor e à instituição escolar para diagnosticar um problema de aprendizagem.

As ações pedagógicas devem ser refletidas e associadas a uma prática educativa coerente com 0 contexto educacional, as quais visam igualdade de oportunidades e de acesso ao conhecimento, mesmo para alunos "menos favorecidos e considerados limitados por uma fraqueza que não Ihes pertence".

Nessa perspectiva, não existem crianças com DA, o que ocorre no sistema de ensino é a privação de situações de aprendizagem que contemplem a forma de aprender dessas crianças. Pode ser que as reais potencialidades do aluno com DA não sejam validadas no contexto escolar. Se a criança estiver inserida em situações de aprendizagem que se adaptem à sua forma natural de aprender, certamente seus potenciais serão desenvolvidos.

O aluno pode apropriar-se do conhecimento por meio das situações de aprendizagem presentes no contexto escolar, em que a pluralidade não pode ser considerada limitação, mas constituir-se nas mais variadas possibilidades. Ao assumir o ensino numa concepção em que todos apresentam as várias inteligências, pode ser necessário uma alteração na forma como se concebe a DA, e principalmente, as práticas pedagógicas que estão inseridas neste contexto.

Diante disso, professor e estudante podem reconhecer que todas as pessoas têm sua própria forma de aprender, sendo que isso se constitui numa característica humana. E, principalmente, admitir que a criança rotulada como "incapaz para a aprendizagem" pode possuir inteligências que, se forem devidamente reconhecidas e estimuladas, contribuirão para o seu desenvolvimento global.

Ao considerar a pluralidade intelectual da criança com DA, Gardner (1994; 2000), por meio de suas pesquisas, apresenta a Teoria das Inteligências Múltiplas. 
Segundo Gardner (1994; 2000), as definições de inteligência dependem não somente dos indivíduos, mas também de seus valores e crenças associadas às necessidades pessoais e propósitos culturais. Dessa forma, indícios múltiplos e convergentes levaram o pesquisador a propor uma maneira de conceber a inteligência que abrange a pluralidade do intelecto.

\section{Inteligências múltiplas}

Na perspectiva da Teoria das Inteligências Múltiplas, todas as pessoas possuem várias inteligências, sendo que a diferença é o estímulo que é dado a cada indivíduo para que seja favorecido o desenvolvimento dessas inteligências (Gardner, 1999).

As inteligências são desenvolvidas em graus variados, dependendo dos estímulos que as pessoas recebem no seu percurso de vida. Os valores culturais vinculam-se às capacidades intelectuais na solução de problemas que decorrem dos objetivos e valores provenientes dos desafios encontrados em cada cultura. Então, além dos fatores genéticos e neurobiológicos, o desenvolvimento de cada inteligência também será determinado por condições ambientais e culturais (Gardner, idem).

Gardner (2000, p.47) apresenta o conceito de inteligência como: "potencial biopsicológico para processar informações, que pode ser ativado num cenário cultural para solucionar problemas ou criar produtos que sejam valorizados numa cultura". O autor argumenta que uma inteligência é um termo para organizar e descrever capacidades humanas e não uma referência a um produto que determina o quanto o indivíduo é "capaz ou incapaz".

Ao abordar valores culturalmente construídos, remete-se à idéia de costumes diferentes e, conseqüentemente, as experiências e oportunidades de desenvolvimento que conduzem a habilidades e valores são diversificadas. Além disso, algumas culturas sequer possuem uma concepção de inteligência, enquanto outras compreendem a inteligência com características próprias. Portanto, a noção de inteligência está fortemente relacionada com a cultura, pois as inteligências só se desenvolvem porque são valorizados pelo ambiente cultural (Gardner, 2000).

Segundo o autor, todos os indivíduos normais são capazes de uma atuação em pelo menos oito diferentes e, até certo ponto, independentes, 
áreas intelectuais. Essa argumentação favorece a compreensão da inteligência como processo individual e contínuo ao longo de toda existência humana (Gardner, 1995). O autor identificou inicialmente sete inteligências: Lingüística, Lógico-Matemática, Espacial, Musical, Corporal Cinestésica, Interpessoal e Intrapessoal. Posteriormente acrescentou a Inteligência Naturalista como sendo a oitava. Cada inteligência possui sua característica própria que a distingue das demais.

"A inteligência lingüística envolve sensibilidade para a língua falada e a escrita, a habilidade de aprender línguas e a capacidade de usar a língua para atingir certos objetivos" (Gardner, 2000: 56). Esta inteligência está relacionada com a habilidade para usar a linguagem para transmitir idéias, sendo expressa, principalmente, pelos poetas, os escritores, os advogados, os locutores e os oradores.

A característica da Inteligência Lógico-Matemática refere-se ao processo de resolução de um problema com lógica. "A inteligência lógicomatemática envolve a capacidade de analisar problemas, com lógica, de realizar operações matemáticas e investigar questões cientificamente" (Gardner, 2000: 56). Apresenta-se expressa principalmente em matemáticos, programadores de computador, analistas financeiros, contadores, engenheiros e cientistas.

Por sua vez, o caráter distinto da Inteligência Musical consiste na sua manifestação em habilidade para apreciar, compor ou reproduzir uma peça musical. "A Inteligência Musical acarreta habilidade na atuação, na composição e na apreciação de padrões musicais" (Gardner, 2000: 57). Inclui discriminação de sons, habilidade para perceber temas musicais, sensibilidade para ritmos, e habilidade para produzir ou reproduzir música. Além disso, a Inteligência Musical permite a criação e a comunicação, bem como a compreensão de significados compostos utilizando-se os sons (Gardner, 1995, 2000; Gardner; Konhaber; Wake, 1998). Essa habilidade está representada pelos compositores, maestros e instrumentistas, assim como peritos em acústica e engenheiros de áudio.

Outra manifestação do intelecto refere-se à Inteligência Espacial. Segundo Gardner, (2000: 57): "[...] deve-se ressaltar que tal inteligência também é usada por deficientes visuais, pois a inteligência espacial não depende da sensação visual. A Inteligência Espacial tem o potencial de reconhecer e manipular os padrões do espaço". 
Além da principal aplicação desta inteligência nas artes visuais, ela também é utilizada entre os geógrafos, cirurgiões, escultores, jogadores de xadrez, artistas gráficos, arquitetos, decoradores e navegadores.

Ao referir-se ao corpo em movimento solucionando problemas, aborda-se a característica da Inteligência Corporal Cinestésica. Essa inteligência se refere à habilidade para resolver problemas ou criar produtos utilizando-se o corpo, ou parte do corpo. Portanto, solicita a coordenação grossa ou fina em esportes e jogos, artes plásticas ou no controle dos movimentos do corpo. "A Inteligência Corporal Cinestésica acarreta o potencial de usar o corpo (como a mão ou a boca) para resolver problemas ou fabricar produtos" (Gardner, 2000: 57). Situações explícitas da manifestação dessa Inteligência referem-se à expressividade dos dançarinos, assim como a habilidade apresentada pelos alpinistas, pelos jogadores de esportes coletivos e pelos mímicos, pois demonstram a capacidade de realizar ações motoras amplas e finas na busca da solução de uma situação problema.

Outra manifestação do intelecto refere-se à Inteligência Interpessoal, a qual abarca a habilidade que emprega capacidades centrais para reconhecer e fazer distinções entre os sentimentos, as crenças e as intenções dos outros. Essa manifestação do intelecto, está bem interpretada pelos terapeutas, professores, vendedores, políticos, líderes religiosos, líderes políticos e atores (Gardner; Konhaber; Wake, 1998; Gardner, 2000).

A Inteligência Intrapessoal relaciona-se com a noção que o indivíduo tem dos próprios sentimentos, referindo-se à capacidade de autoconhecimento que ele possui. Em seu nível mais avançado, a inteligência intrapessoal consolida discriminações avançadas dos próprios sentimentos, intenções e motivações, que trazem um elevado nível de autoconhecimento (Gardner; Konhaber; Wake, 1998). Gardner (2000) relata a Inteligência Intrapessoal como imprescindível nas decisões pessoais. Além disso, o autor considera mais o aspecto peculiar das emoções, do que emoções reduzidas somente a determinados tipos de inteligência. "Além do mais, agora considero mais as facetas emocionais de cada inteligência do que as emoções restritas a uma ou duas inteligências pessoais" (p. 58).

A Inteligência Naturalista é demonstrada no reconhecimento e na classificação de numerosas espécies da flora e da fauna. Essa demonstração 
de Inteligência está expressa pelos indivíduos de vasto conhecimento sobre os seres vivos. Essa manifestação do intelecto se refere à habilidade em lidar com situações ligadas a natureza, e está bem representada pelos biólogos, cientistas naturalistas, paisagistas e ambientalistas.

Estas inteligências até certo ponto são independentes, contudo elas não funcionam isoladamente. A partir dessa premissa, a qual preconiza que os seres humanos dispõem de graus variados de cada uma dessas inteligências, os quais resultam das maneiras diferentes de combiná-las e organizá-las, para alguns propósitos em determinadas culturas, pode ser importante explorar as mais variadas combinações de inteligência. Com todas essas proposições, embora Gardner não tenha concebido a Teoria especificamente para a área educacional, devido ao fato de se analisar a importância das diversas formas de pensamento, juntamente com a relação existente entre aquisição do conhecimento e cultura, as implicações da Teoria das Inteligências Múltiplas tornaram-se explícitas para educação.

\section{A teoria das inteligências múltiplas na aprendizagem}

Ao considerar a diversidade que apresenta o contexto escolar, assim como as muitas variáveis que interferem no processo de aprendizagem, os métodos de ensino podem considerar a concepção de uma educação vinculada à Teoria das Inteligências Múltiplas (Gardner, 1994, 2000; Armstrong, 2001; Brandl, 2005; Smole, 2006; Vecchi, 2006; Zylberberg, 2007).

Ao conceber as práticas pedagógicas sob a visão das Inteligências Múltiplas os conteúdos podem ser ensinados nas mais diversas abordagens pedagógicas. Porém, ao planejar uma educação realmente eficaz, os métodos devem ser suscetíveis às estimulações do potencial, e conseqüentemente, à compreensão dos estudantes.

Quando as ações pedagógicas permitem a influência da Teoria das Inteligências Múltiplas, certamente poderá introduzir inovações interessantes em suas práticas, oferecendo mais oportunidades para que cada aluno encontre seu próprio percurso de aprendizagem.

Além disso, para Nista-Piccolo e colaboradores (2004) ao abranger o ser humano com múltiplos potenciais ocorre o favorecimento de uma concepção de ensino centrado nos potenciais individuais do aprendiz, 
desencadeando o desenvolvimento de todos os tipos de inteligências, característicos de seus potenciais.

Nessa perspectiva, pode-se conceber uma combinação própria de inteligências para cada ser humano, que pode fornecer indícios no seu percurso de aprendizagem, como também nas dificuldades encontradas nesse percurso.

Em suas propostas, Macedo (2005), Feldman (2001), Gardner (2000), Smole (2006) e Zylberberg (2007) defendem a escola como parte integrante de uma sociedade complexa, a qual deveria oferecer às crianças uma aprendizagem a partir da singularidade e diversidade, praticando a reflexão e ao mesmo tempo refletindo sobre a prática. Para esses autores, reconhecer essa diversidade no contexto escolar é uma necessidade e uma excelente perspectiva para focar reformas educacionais.

Os autores propõem uma reflexão sobre diferenças, permitindo talvez que essa compreensão gere uma crítica ao que está sendo proposto, e o que está sendo realizado para possibilitar um ensino realmente acessível a todos.

\section{A pesquisa}

A partir das análises bibliográficas sobre os temas referentes à Aprendizagem, Dificuldade de Aprendizagem e Inteligências Múltiplas, alguns questionamentos foram levantados: Como criar situações de estímulos pautados na Teoria das Inteligências Múltiplas, em crianças diagnosticadas no contexto escolar como possuidoras de DA? Será que essa pode ser uma alternativa facilitadora para a aquisição e expressão do conhecimento?

Para responder a essas indagações, o objetivo principal dessa investigação, se constituiu em verificar a possibilidade de ampliar a aquisição, manifestação e expressão do conhecimento, por parte dessas crianças, classificadas como possuidoras de DA no contexto escolar, utilizando situações de estímulos das Inteligências Múltiplas como rotas de acesso no processo de ensino e aprendizagem.

As questões que envolvem a Aprendizagem e DA no contexto escolar se apresentam de forma complexa. Nessa perspectiva, o método de análise proposto pelo Paradigma Indiciário, desvelado por Ginzburg (1989), mostrouse como o mais apropriado para a compreensão desse universo. 


\section{O percurso metodológico da investigação}

Esse trabalho foi desenvolvido em uma Escola Pública brasileira, situada em uma cidade da Grande São Paulo. A escolha dessa unidade como local do estudo foi devido a pesquisadora atuar como docente nessa escola, facilitando assim a realização das Intervenções Pedagógicas.

Como primeiro passo, o projeto de pesquisa foi apresentado à Direção da escola. Após uma análise preliminar, a Direção da escola indicou uma turma da quarta série, do ensino fundamental, para serem os alunos participantes desse estudo, pois estavam agrupados e classificados como retidos, e segundo diagnóstico escolar todos apresentavam DA.

As inquietações direcionaram a uma pesquisa documental sobre a vida escolar desses alunos, junto à secretaria da escola. Foi realizado um levantamento de todos os registros referentes aos anos anteriores, além de dados atuais. A classe escolhida era composta por treze alunos, um número bastante reduzido, comparado às outras quartas séries, as quais são constituídas de quarenta alunos, no mínimo. Todos cursavam a quarta série do Ensino Fundamental pela segunda vez.

No contexto escolar, as questões que envolvem demonstração de DA são sempre muito complexas, necessitando de vários olhares para uma mesma questão. Era necessário saber ainda: Quem são essas crianças que apresentam DA no contexto escolar? Qual a percepção dos pais, dos professores e da direção da escola em relação a essas crianças? O que poderia facilitar a aquisição, manifestação e expressão do conhecimento por parte dessas crianças? Assim, para revelar os caminhos facilitadores da aprendizagem desses alunos, era preciso realizar entrevistas com todos que estavam atuando com essas crianças.

Os dados coletados nas entrevistas ajudaram a dar pistas de como proceder pedagogicamente com essas crianças. O próximo passo consistiu em elaborar e ministrar as Intervenções Pedagógicas.

Partindo de pontos que emergiram nos estudos sobre Aprendizagem, DA e Inteligências Múltiplas, foram realizadas propostas pedagógicas de ensino, por meio de situações problemas, com ênfase no trabalho motor, visando estimular as Múltiplas Inteligências dessas crianças. 
As atividades foram desenvolvidas pela professora de Educação Física e pesquisadora, com início em agosto e término em dezembro de 2006 , totalizando quarenta e uma aulas. Os materiais pedagógicos utilizados foram fornecidos pela escola e/ou confeccionados pelos alunos. As atividades foram realizadas fora do período regular das crianças, numa freqüência de três encontros semanais de aproximadamente 60 minutos cada, totalizando 41 aulas.

Os conteúdos constituíam-se em brincadeiras que envolviam além dos movimentos corporais, convivência social, atividades musicadas, danças, dramatizações, verbalizações, trabalhos de recorte e colagem, jogos de dramatização, movimentos expressivos, atividades rítmicas, circenses e cênicas.

Segundo Brandl (2005), a manifestação da Inteligência Corporal Cinestésica no contexto escolar implica em resolver problemas, criar e recriar manifestações da cultura a partir do potencial de cada um, o que nos pode indicar também novas abordagens para a prática pedagógica. A autora realizou um estudo em que relaciona as questões da aprendizagem vivenciadas na escola com a possibilidade de se proporcionar a estimulação das inteligências, em especial nas aulas de Educação Física, as quais podem favorecer principalmente as manifestações da Inteligência Corporal Cinestésica. Em sua pesquisa esclarece que no contexto escolar para ser possível uma reflexão sobre o processo de ensino e aprendizagem é preciso conceber o ser humano em toda sua complexidade. Assim: "[...] concebemos os seres humanos como complexos, inteiros, unos e a partir de sua corporeidade, para daí pensar o processo de ensino e aprendizagem como forma de estimulação das inteligências". Foi baseando-se nessa perspectiva que esse estudo se fundamentou.

Por meio dos dados levantados nas entrevistas e observações feitas durante a realização das Intervenções Pedagógicas, buscou-se elencar indícios de possíveis facilitações na aquisição, expressão e manifestação do conhecimento por parte desses alunos. A evolução mostrada nos procedimentos adotados em aula pode ser o indício mais forte de aprendizagem dos alunos. Cada um, na sua própria individualidade, foi demonstrando progresso em seu comportamento, se comparado com aqueles apresentados no início do programa de intervenção. 
Os indícios deflagrados até aquele momento da investigação trouxeram muito interesse em saber qual era a percepção dos professores, dos pais e da psicóloga a respeito desses alunos após a realização da Intervenção Pedagógica. Então, surgiu a necessidade de voltar aos entrevistados para verificar se expressavam alguma percepção diferenciada dos indícios revelados antes dessa fase do projeto.

Foram realizadas novamente as entrevistas com os pais, com a equipe pedagógica e administrativa, todos que estavam envolvidos com essas crianças.

Considerando que os dados levantados suscitam a busca de sinais, com base no Paradigma Indiciário, nossa meta era identificar as pistas presentes nos discursos de todos esses entrevistados, bem como, os sinais revelados durante a fase de aplicação das Intervenções Pedagógicas, expressos por esses alunos que, segundo o contexto escolar, apresentavam DA.

\section{Revelando os indícios}

Antes do período das Intervenções pedagógicas, foram revelados indícios referentes a algumas questões como indisciplina, motivação, o medo do fracasso, a falta de expressividade, o conformismo demonstrado pelos pais, a hiperatividade, a carência afetiva, a falta de envolvimento da família e a falta de interação entre professor-aluno, apontados pelos entrevistados como sinais que favoreciam a DA.

Quanto às atitudes pedagógicas e administrativas tomadas pelos envolvidos frente às DA expressadas por esses alunos, foi possível observar, por meio dos indícios presentes nos seus próprios depoimentos, certas incoerências no que se refere ao conteúdo programático relacionado com as reais possibilidades dos alunos e professores, além da falta de apoio da escola que só determinava o encaminhamento dos alunos para tratamentos psicológicos.

Após o período das Intervenções Pedagógicas, na segunda etapa das entrevistas, foi possível perceber que assiduidade das crianças nos encontros foi um fator que parece ter repercutido também em outras aulas. Mais do que isso, os alunos também começaram a se relacionar melhor, diminuindo os 
conflitos entre eles, proporcionando um ambiente mais propício à aprendizagem.

Indícios múltiplos apontavam que as relações interpessoais se manifestavam de forma positiva. Percebeu-se que todas as crianças demonstravam maior envolvimento com as propostas pedagógicas e até mesmo aprimoravam-se nas várias formas de expressão do conhecimento. Também foi possível perceber que o compromisso, a motivação, a organização e o relacionamento entre eles se apresentavam de forma positiva após a realização dessas Intervenções Pedagógicas.

Por sua vez, a indisciplina, embora tenha se repetido como um fator que interferia nas ações pedagógicas, já se mostrava em menor freqüência. Podemos dizer que se compararmos os indícios revelados antes das Intervenções Pedagógicas que apresentaram real melhora foram aqueles relacionados às questões da auto-motivação, da disciplina, da interação, da auto-estima, do compromisso, da criatividade, influenciando na expressividade do conhecimento e na assiduidade deles na escola. Portanto, houve significativa melhora após o período de aplicação das Intervenções Pedagógicas.

\section{Considerações finais}

Essa investigação procurou compreender como as crianças com DA no contexto da escola aprendem, baseando-se no princípio de que todos os estudantes, embora classificados como possuidores de DA, apresentam uma pluralidade intelectual. A partir da fundamentação da Teoria das Inteligências Múltiplas, o processo de aprendizagem é único para cada indivíduo, assim como o princípio pedagógico se constitui no respeito às individualidades e principalmente às várias formas de expressividade do ser humano.

Porém, cabe ressaltar que para uma prática pedagógica nessa perspectiva, não se trata simplesmente de relatar que todos nós somos diferentes, mas para que ocorra a aprendizagem, a sociedade e a escola precisam transcender o discurso da diversidade humana, da pluralidade intelectual e realmente desenvolverem ações sociais, políticas e pedagógicas comprometidas com a complexidade do ser humano. 
$\mathrm{O}$ ato de generalizar, fragmentar e homogeneizar seres aprendizes propicia a exclusão de valores, e das possibilidades de aprendizagem e desenvolvimento, reduzindo, e até mesmo anulando, capacidades ilimitadas. Uma educação que prioriza a criança suscita e exige da escola uma pedagogia comprometida com intervenções sociais e globais. Assim, o grande desafio da escola pode se constituir em representar as individualidades, considerando a diversidade existente no seu contexto.

A educação deve tratar o ser humano em toda sua dimensão, tendo como foco 0 indivíduo, rompendo com uma visão reducionista de Aprendizagem, DA e Inteligência. Além disso, não se pode ter uma visão que enfatiza a responsabilidade do sucesso da aprendizagem sobre a criança, ou sobre o professor. Pode ser que a responsabilidade do insucesso da aprendizagem seja de todo um Sistema Educacional e nessa dura realidade, o professor torna-se o grande vilão da aprendizagem, e o papel de vítima é do aluno.

Mas, apesar da evidência de que a responsabilidade pedagógica não é somente do professor, a partir do momento em que o professor olhar para todas as crianças, como alunos que possuem várias inteligências, pode ser 0 início da mudança de histórias de fracassos tanto de alunos, como de professores.

Os resultados desse estudo revelam a possibilidade de Intervenções Pedagógicas, baseadas, na pluralidade intelectual. Entretanto, é preciso considerar todas as variáveis do contexto escolar, assim como a articulação dessas variáveis. Além disso, conceber a Teoria das Inteligências Múltiplas no ensino público não se constitui em uma prática simples, mas se apresenta como um enorme desafio para todos os envolvidos na educação.

Para aplicar uma metodologia baseada nessa Teoria as estratégias pedagógicas devem conceber que não existem incapacidades para aprendizagem. Para tanto, na escola pública, torna-se imprescindível um engajamento dos professores, dos pais, dos alunos, da equipe administrativa, enfim de todos os envolvidos no sistema escolar, juntamente com a ruptura de alguns Paradigmas Educacionais.

Além disso, cabe atentar que no ensino público os alunos, os professores, os diretores, os pais enfrentam uma dura realidade, sendo que os descasos prevalecem, e muitas vezes estão além do contexto escolar, pois 
estão inseridas na história de vida da criança e na sociedade. Diante dessa realidade do contexto escolar, as propostas pedagógicas que envolvem equipe administrativa, os docentes e os discentes, na educação pública, estão pautadas num enorme desafio: "matar um grande leão a cada dia".

\section{Referências}

AMARO, Deigles J. (2006). Educação Inclusiva e o Cotidiano Escolar. São Paulo: Casa do psicólogo.

ARMSTRONG, Thomaz (2001). Inteligências Múltiplas na Sala de Aula. Porto Alegre: Artmed.

BRANDL, Carmen E. H. (2005). A Estimulação da Inteligência Corporal Cinestésica no Contexto da Educação Física Escolar. Tese de Doutorado em Educação Física. Faculdade de Educação Física, Universidade Estadual de Campinas, Brasil.

CIASCA, Sylvia M. (2003). Distúrbios de Aprendizagem: proposta de avaliação interdisciplinar. São Paulo: Casa do psicólogo.

FELDMAN, David H. (2001). Como o Spectrum começou. In J.-Q. Chen; M. Krechevsky; J. Viens (Orgs.), Projecto Spectrum: Utilizando as competências das crianças. Porto Alegre: Ática.

FERNÁNDEZ, Alicia (1991). A Inteligência Aprisionada: abordagem psicopedagógica clinica e sua família. Porto Alegre: Artes Médicas.

GARDNER, Howard (1994). Estruturas da Mente: a teoria das inteligências múltiplas. Porto Alegre: Artes Médicas.

GARDNER, Howard (1995). A Criança Pré-escolar: como pensa e como a escola pode ensiná-la. Porto Alegre: Artes Médicas.

GARDNER, Howard (1998). O Guru das Inteligências Múltiplas. Pátio: Revista Pedagógica. Porto Alegre: v. 1, n. 1, pp. 34-37, maio/jul.

GARDNER, Howard (1999). O Verdadeiro, o Belo e o Bom: os princípios básicos para a nova educação. Rio de Janeiro: Objetiva.

GARDNER, Howard (2000). Inteligência: um conceito reformulado. Rio de Janeiro: Objetiva.

GARDNER, Howard (2006). A Arte de Mudar as Mentes. Pátio: Revista Pedagógica. Porto Alegre: v. 1 n.38,pp. 20-22, maio/jul.

GARDNER, Howard; KORNHABER, Mindy L.; WAKE, Warren (1998). Inteligência: múltiplas perspectivas. Porto Alegre: Artmed.

GINZBURG, Carlos (1989). Sinais: raízes de um paradigma indiciário. In C. Ginzburg, Mitos, Emblemas, Sinais. Morfologia e História. Tradução de Frederico Carotti. São Paulo: Companhia das Letras.

LUCKESI, Cipriano C.( 1999). Filosofia da Educação. São Paulo: Cortez.

MACEDO, Lino de (2005). Ensaios Pedagógicos: como construir uma escola para todos? Porto Alegre: Artmed. 
MACHADO, Adriana M.( 1997). A queixa no alvo do diagnóstico. Série ldéias n. 28. São Paulo: FDE, pp. 141- 156.

NEIRA, Marcos G. (2003). Educação Física: desenvolvendo competências. São Paulo, Phorte.

NISTA-PICCOLO,Vilma L.; PRODÓCIMO, Elaine; SOUZA, Mauricio T.; BRANDL, Carmen E. H.; ZYLBERBERG, Tatiane P.; FARIAS, Luciene (2004). Manifestações da inteligência corporal cinestésica em situação de jogo na educação física escolar. Revista Brasileira de Ciência e Movimento, 12, n 4, pp. 01-126.

OSTI, Andréa (2004). As dificuldades de aprendizagem na concepção do professor. Dissertação de Mestrado em Educação. Faculdade de Educação, Universidade Estadual de Campinas, Campinas.

PATTO, Maria H. S. (1998). O fracasso escolar como objeto de estudo: anotações sobre as características de um discurso. Cadernos de Pesquisa, n.65, pp.72-77, maio.

SMOLE, Kátia C. S. (2006). Aprendizagem Significativa: o lugar do conhecimento e da inteligência. [Acedido em 30-05-2007, disponível em http: www.maristas. org.ber/downloads/sisnot/2006/inteligenciasmultiplaskatia.doc].

VECCHI, Rodrigo L. (2006). Ensinar para a compreensão: proposta de uma fundamentação teórica para a Educação Física Escolar. Dissertação de Mestrado em Educação Física. Faculdade de Educação Física, Universidade São Judas Tadeu, São Paulo.

VYGOTSKI, Lev S. (1991). A Formação Social da Mente: o desenvolvimento dos processos psicológico superiores. 4. ed. São Paulo: Martins Fontes.

WADSWORTH, Barry J. (2003). Inteligência e Afetividade da Criança na Teoria de Piaget. São Paulo: Pioneira.

WEISZ, Telma; SANCHEZ, Ana (2003). O Diálogo entre Ensino e Aprendizagem. São Paulo: Ática.

ZYLBERBERG, Tatiane P. (2007). Possibilidades corporais como expressão da inteligência humana no processo ensino-aprendizagem. Tese de Doutorado em Educação Física. Faculdade de Educação Física, Universidade Estadual de Campinas, UNICAMP- Campinas. 


\title{
LEARNING DIFFICULTIES FROM THE PERSPECTIVE OF MULTIPLE INTELLIGENCES: A STUDY WITH A GROUP OF BRAZILIAN CHILDREN
}

\begin{abstract}
The text presents a study with thirteen Brazilian children enrolled in the fourth grade of elementary education of the public school system from Estado of São Paulo, diagnosed as having learning difficulties. The objective was to investigate the possibility of increasing the acquisition and expression of knowledge among these children. Sustained by the literature review about Learning, Learning difficulties and Multiple Intelligences, pedagogical interventions have been developed aiming at promoting the intellectual diversity of those students. For the analysis we opted for the method suggested by Ginzburg (1989): the evidential paradigm. The data were collected by means of interviews and observations during the pedagogical interventions and showed signs that may have promoted learning disabilities in the school context. After the pedagogical intervention period, we concluded that motivation, discipline, interaction, self-esteem and expressiveness improved considerably. Moreover, data showed evidence that encourage learning, developed in the course of the pedagogical interventions
\end{abstract}

Keywords

Learning; Learning difficulties; Multiple intelligences 


\title{
DIFFICULTÉS D'APPRENTISSAGE DANS LA PERSPECTIVE DES INTELLIGENCES MULTIPLES: UNE ÉTUDE AVEC UN GROUPE D'ENFANTS BRÉSILIENS
}

\begin{abstract}
Résumé
Le texte présente une étude avec treize enfants brésiliens inscrits en quatrième année de l'enseignement élémentaire d'une école publique de l'Etat de São Paulo. Ces élèves ont été diagnostiqués comme porteurs de difficultés d'apprentissage. L'objectif était d'étudier la possibilité de développer l'acquisition, l'expression et l'expression des savoirs par ces enfants. Partant d'une revue de la littérature sur apprentissage, difficultés d'apprentissage et intelligences multiples, on a fait des interventions pédagogiques pour stimuler la diversité intellectuelle de ces étudiants. Le paradigme indiciaire de Ginzburg (1989) a été usé comme méthode d'analyse. Les données recueillies lors des interviews et des observations au cours des interventions ont montré possibles raisons pour le développent des difficultés d'apprentissage en contexte scolaire. Après le période de l'intervention pédagogique on peut conclure que la motivation, la discipline, l'interaction, l'estime de soi et l'expression ont été amélioré considérablement. En outre, les données ont montré des indices qui encouragent l'apprentissage, construits dans le cadre des interventions pédagogiques.
\end{abstract}

Mots-clé

Apprentissage; Difficultés d'apprentissage; Intelligences multiples

Recebido em Março/2009

Aceite para publicação em Junho/2010

\footnotetext{
Toda a correspondência relativa a este artigo deve ser enviada para: Vera Lúcia Teixeira da Silva, Rua Dr. Almiro dos Reis, 54 BL A, apto 4, Jardim Lapena, Cep 08071-170, São Paulo, Brasil. E-mail: verateixer@hotmail.com
} 